\title{
Correction to: Cost-effectiveness of rule-based immunoprophylaxis against respiratory syncytial virus infections in preterm infants
}

\author{
Maarten O. Blanken ${ }^{1} \cdot$ Geert W. Frederix ${ }^{2} \cdot$ Wendy J. Ungar ${ }^{3,4} \cdot$ Elisabeth E. Nibbelke ${ }^{1} \cdot$ Hendrik Koffijberg $^{5}$. \\ Elisabeth A. M. Sanders ${ }^{1}$. Maroeska M. Rovers ${ }^{6}$. Louis Bont ${ }^{1}$ - on behalf of the Dutch RSV Neonatal Network
}

Published online: 22 November 2019

(C) Springer-Verlag GmbH Germany, part of Springer Nature 2019

\section{Correction to: Eur J Pediatr (2018) 177:133-144 \\ https://doi.org/10.1007/s00431-017-3046-1}

The name of the co-author Wendy J. Ungar, who contributed significantly to the research project, was inadvertently omitted from the original published article; she supervised the development of the economic model. Her name and affiliation have now been added to the author list. The original article remained unchanged.

Publisher's note Springer Nature remains neutral with regard to jurisdictional claims in published maps and institutional affiliations.

The online version of the original article can be found at https://doi.org/ 10.1007/s00431-017-3046-1

Louis Bont

1.bont@umcutrecht.nl

Maarten O. Blanken

m.o.blanken-2@umcutrecht.nl

Geert W. Frederix

G.W.J.Frederix@umcutrecht.nl

Elisabeth E. Nibbelke

L.Nibbelke@umcutrecht.nl

Hendrik Koffijberg

h.koffijberg@utwente.nl

Elisabeth A. M. Sanders

L.Sanders@umcutrecht.nl

Maroeska M. Rovers

maroeska.rovers@radboudumc.nl
1 Division of Pediatric Immunology and Infectious Diseases, University Medical Center Utrecht, P.O. Box 85090, 3508 AB Utrecht, the Netherlands

2 Division Julius Center for Health Sciences and Primary Care, University Medical Center Utrecht, Utrecht, The Netherlands

3 Child Health Evaluative Sciences, The Hospital for Sick Children Research Institute, Toronto, Canada

4 Institute of Health Policy, Management and Evaluation, University of Toronto, Toronto, Canada

5 Department of Health Technology and Services Research, University of Twente, Enschede, The Netherlands

6 Departments of Epidemiology, Biostatistics and HTA, and Operating Rooms, Radboud University Nijmegen Medical Center, Nijmegen, The Netherlands 